\title{
Research Paper: Effectiveness of Acceptance and Commitment Therapy on Hope in Women With Breast Cancer Undergoing Chemotherapy
}

\author{
Saeedeh Dadashi' ${ }^{1}$, Fereshte Momeni ${ }^{2 *}$ \\ 1. Department of Clinical Psychology, Faculty of Management and Accounting, Qazvin Branch, Islamic Azad University, Qazvin, Iran. \\ 2. Department of Clinical Psychology, University of Social Welfare and Rehabilitation Sciences, Tehran, Iran.
}

\begin{tabular}{|c|c|}
\hline $\begin{array}{l}\text { Use vour device toscan } \\
\text { and reat theartico online }\end{array}$ & \\
\hline$\square \operatorname{arn}$ & Ittation: Dadashi, S., \& Momeni, F. (2017). Effectiveness of Acceptance and Commitment Therapy on Hope in Women With \\
\hline 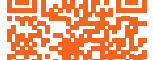 & $\begin{array}{l}\text { Breast Cancer Undergoing Chemotherapy. Journal of Practice in Clinical Psychology, 5(2), 107-114. https://doi.org/10.18869/ } \\
\text { acadpub.jpcp.5.2.107 }\end{array}$ \\
\hline 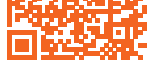 & doi): ${ }^{\prime}$ https://doi.org/10.18869/acadpub.jpcp.5.2.107 \\
\hline
\end{tabular}

Article info:

Received: 21 Nov. 2016

Accepted: 05 Feb. 2017

Keywords:

Breast cancer, Hope, Acceptance and commitment therapy

\begin{abstract}
Objective: The present research aimed to assess the effectiveness of Acceptance and Commitment Therapy (ACT) on the hope of patients with breast cancer undergoing chemotherapy.

Methods: In this quasi-experimental study, 30 patients with breast cancer were selected by convenience sampling method and randomly assigned to experimental and control groups. The experimental group attended ACT sessions for 8 weeks continuously (each session lasting 45 minutes). Customers/clients in both the experimental and control groups completed Snyder hope scale as pretest and posttest. Analysis of covariance was used as the statistical method.
\end{abstract}

Results: The findings suggest that ACT is an effective treatment for breast cancer treated patients $(\mathrm{P}<0.001, \mathrm{~F}=279.025)$, including those with low levels of hope.

Conclusion: The results showed that ACT is an effective method in rising hope in women with breast cancer. Thus, psychological interventions can be used to increase the hope of women with breast cancer.

\section{Introduction}

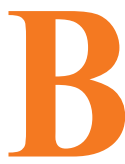

reast cancer is becoming an increasingly significant global public health threat, affecting women of all socioeconomic levels in both developed and developing countries

(Knaul et al., 2009). Although rates of breast cancer mortality in developed countries have historically been far greater than those in developing countries (Ferlay et al., 2008), trends suggest that breast cancer mortality rates among women in Latin America are rapidly increasing (Jemal, Center, DeSantis, \& Ward, 2010). In Mexico, breast cancer has emerged as the leading cause of death in women with malignancies (Knaul et al., 2009) following the pattern of breast cancer mortality seen among U.S. Latinas (American Cancer Society, 2011).

There has been a steady improvement in patient survival in recent decades as a result of a combination of early

\footnotetext{
* Corresponding Author:

Fereshte Momeni, PhD

Address: Department of Clinical Psychology, University of Social Welfare and Rehabilitation Sciences, Tehran, Iran.

Tel: +98 (912) 5037212

E-mail:fm.psychologist@yahoo.com
} 
detection (thanks to advances in mammographic screening) (Kopans, 2011) and adjuvant systemic chemotherapy (Peto et al., 2012). Excluding skin cancers, breast cancer is the most common cancer diagnosed among women in the United States, accounting for nearly 1 in 3 cancers (Torre et al., 2015), with an estimated rate of 232340 new cases and 39620 deaths in 2013 (Siegel, Naishadham, \& Jemal, 2013). It is also the second leading cause of cancer death after lung cancer among women. Breast cancer is a very common disease that affects approximately 1 in 10 women at some point in their lives (Valent et al., 2012). In a study conducted in Iran by the prevalence of $41.4 \%$, breast cancer was the most common type of cancer in women between the years 2000 to 2009 (Tayebi, Shabestani Monfared, Moslemi, 2012).

Breast cancer is the most prevalent cancer in Iranian women and the fifth most common cause of cancer-related death in Iran (Akbari et al., 2011). Psychological damage of the breast cancer to patient is serious. Approximately $30 \%$ of patients with the early breast cancer are diagnosed as depressed mental status before operation (Falagas et al., 2007). Patients with breast cancer have to receive hormone therapy, chemotherapy, and radiation therapy for a long term after operation (Kamio, Schmidt, Germann, Kubanek, Derby, 2013). Cancer treatment process is complex and frequently associated with severe side effects and complications that influences the physical, psychological, and social dimensions of life for cancer patients and their families (Liao et al., 2014).

Women with visceral cancer have a shorter life expectancy. Mean survival for women with skeletal cancer has increased from 24 to 36 months, and women with a more indolent disease may live for many years (10-15 years in some cases). The prognosis of breast cancer has improved largely due to advances in more effective and better-tolerated therapies, but this has also resulted in more complex survivorship problems for these patients with a high need for psychological support (Reed, Simmonds, Haviland, \& Corner, 2012). The impact of living with breast cancer is considerable with many patients experiencing cancer related fatigue and psychological symptoms such as anxiety and depression (Eyles et al., 2015).

Despite the large number of psychological intervention studies for individuals diagnosed with cancer, the overall efficacy of these treatments in addressing patient symptom burden has been heavily debated (Sanford et al., 2014). A recent meta-analysis of 61 trials demonstrated that psychological distress moderated the efficacy of psychosocial treatments regarding mood management for cancer patients (Schneider et al., 2010). Furthermore, a meta-analysis of trials targeting cancer patients indicated that psychotherapeutic and pharmacological interventions are effective in reducing depression and anxiety and increasing hope and quality of life (Mustian et al., 2013).

Hope can be defined as a subjective probability of good outcomes, (Jafari et al., 2010) representing the feeling of an optimistic future for men, which allows for the establishment of plans and long-term goals (Chang, Yu, \& Hirsch, 2013). In the face of daily situations, people tend to anchor their hope in issues that are significant to them, either external, such as family, friends or something supernatural; or internal, when people deposit their hopes on themselves, thinking about their lives and possibility of personal achievements (Du \& King, 2013). We explore levels of hope in individuals who experience chronic diseases, to verify the impact of this feeling at times of hardships and trials, due to its importance in the coping process of ill patients. The feeling of hope has been investigated in patients with cancer undergoing antineoplastic treatment (Ripamonti et al., 2012) and the presence of moderate levels of hope was identified in them.

Given these considerations, there is a need to verify the hope of patients who will begin chemotherapy, since the support of this feeling during therapy strengthen their experience, despite the difficulties imposed by the course of the disease and its treatment (Ahmed, Jabeen, Inayat, \& Hasan, 2013). Furthermore, being aware of their levels of hope during therapy can expand the possibilities of care to these individuals, because in such moments, hope becomes a feeling capable of making people envision a horizon of life with new perspectives, starting to believe in good times even when a chronic disease like cancer arises in their life, and brings with it the stigma of incurability and a long painful treatment (Wakiuchi, Aparecida Marchi, Sharlise Norvila, Silva Marcon, \& Aparecida Sales, 2015). It is possible for people with greater sense of agency and pathways to pursue goals (i.e. high hope) more effective than those with low hopes. Accordingly, in this study we review the effect of hope on patients' adjustment to breast cancer (Stanton et al., 2000).

Researchers are increasingly investigating modern contextual forms of Cognitive Bhavior Therapy (CBT) for psychological disorders that emphasize acceptance and commitment therapy (ACT) and mindfulness strategies (Tai \& Turkington, 2009). Despite research suggesting that acceptance is important for patients with cancer, majority of interventions focus on relaxation/ anxiety reduction techniques, problem solving, psychoeducation, and cognitive-behavioral strategies (Osborn, Demoncada, \& Feuerstein, 2006). 
ACT uses mindfulness and behavior change methods to produce greater psychological flexibility. Psychological flexibility is defined as fully facing the present moment as a conscious human being, and based on what the situation affords, changing or persisting in behavior in the service of chosen values (Hayes, Strosahl, \& Wilson, 2011). ACT aims to increase psychological flexibility, and thereby improving the individual function that is done by 6 processes, including acceptance, diffusion, self as context, contact with present moment, clarifying values, and committed action (Hayes, Luoma, Bond, Masuda, \& Lillis, 2006). Indeed, ACT therapists encourage clients to recognize and reduce unhelpful struggle with psychological content and develop a more accepting stance to be able to move in a valued direction (Bloy, Oliver, \& Morris, 2011).

The literature review indicates that ACT has significant effects on chronic pain, anxiety disorders, obsessional compulsive disorder, and also mental health promotion. Also, studies showed that ACT may be effective for a variety of disorders, including several anxiety disorders, depression, pain, trichotillomania, psychotic disorder, drug abuse and the management of epilepsy and diabetes (Mohabbat-Bahar, Maleki-Rizi, Akbari, \& Moradi-Joo, 2015). We designed a clinical trial to examine the effects of training based on ACT on hope in women with breast cancer.

This preliminary study examined the effectiveness of ACT intervention on increasing hope among patients with cancer. It was hypothesized that over the course of the intervention, patients would report increased psychological flexibility through acceptance of unpleasant thoughts and feelings, and that increased psychological flexibility would lead to improvements in their distress, mood, and hope.

\section{Methods}

This research design was an experimental research with pretest-posttest and a control group. ACT was done on the patients as the intervention. The intervention consisted of 4 modules comprising the essential ingredients of ACT. The modules were covered in 8 therapy sessions. Although each session focused on a specific module, the core elements of ACT were present in every session. Every session also encouraged committed action. All 8 sessions (once a week) was done individually and according to the treatment protocol of Feros et al. (2013).

Four modules were as follows: 1) Increasing effective action orientation (sessions 1-3); it aimed to develop cus- tomers' awareness of distressing thoughts and feelings. It helped customers recognize and let go of unhelpful emotion control strategies. It utilized ACT methods (e.g. diffusion) to reduce behavioral reactivity to emotions and thoughts and increase the extent to which a person is able to choose actions based on what they care about (rather than being dominated by emotions and thoughts), 2) Mindfulness (sessions 4-6); customers were encouraged to engage in mindfulness practices to increase awareness of their distressing thoughts and feelings without having to change them. They also became aware that they could choose to act effectively even when experiencing distress. Finally, they learn to use mindfulness to better connect with what they care about, 3) Self as context (session 7); this module aimed to develop customers' sense of self as separate from their distressing thoughts and feelings. Customers apply it to develop a position from which they could observe their distressing self-concepts and let them come and go, secure in the knowledge that they were the container (context) for these concepts and were not equivalent to them, 4) Formal value clarification and commitment (sessions 8); this section involves helping customers identify what they value in a number of areas, including relationships, health, education, and spirituality. At the end of this module, customers clearly articulate their values and link these to action plans.

This study is a clinical trial with a control group that used the quasi-experimental design to examine the differences in the hope as dependent variables for patients with breast cancer before and after one course of ACT as independent variable pretreatment and posttreatment. Thirty subjects with breast cancer were selected by convenience sampling method.

Inclusion criteria for the study sample were: 1) aged between 30 and 60 years; 2) having at least a high school diploma; 3) diagnosed with breast cancer in stages II or III in patients who completed standard therapies; 4) having undergoing chemotherapy.

Exclusion criteria were as follows: 1) having history of psychotic disorders, bipolar disorder, severe personality disorders or other cancers, 2) simultaneous participation in other psychological courses, 3) lack of psychoactive substance use, addiction to drugs or alcohol.

In this study, the experimental group included 3 patients that had elementary education $(20 \%), 5$ patients (33.33\%) were diploma and 7 patients $(46.66 \%)$ had bachelor. Also, 11(73.33\%) cases were in stage II and $4(26.66 \%)$ patients in stage III. Participants in the control group comprised 15 patients with breast cancer. 
The mean age of participants was 42 years (35-52 y). 4 patients $(26.66 \%)$ had elementary education, 5 patients $(33.33 \%)$ were diploma and 6 patients $(40 \%)$ had bachelor Seven $(46.66 \%)$ cases were in stage II and $8(53.33 \%)$ patients were in stage III. Also, the minimum and maximum age of patients were 35 and 51 years, respectively.

The study instrument was Snyder hope questionnaire Hope was assessed with the adult trait hope scale (Snyder et al., 1991). The scale comprised 12 items, with 4 items each assessing agency (e.g., "I energetically pursue my goals") and pathways thinking (e.g., "There are lots of ways around any problem"). Items are rated on a 4-point scale (from 1, definitely false to 4, definitely true). Snyder et al. (1991) reported its coefficient $\alpha$ ranging from 0.74 to 0.84 for the total scale. For this sample, the coefficient $\alpha$ reliability was 0.76 . In Iran, the validity of the questionnaire was assessed on 100 students and the Cronbach $\alpha$ coefficients were obtained for the components of agency as 0.71 and pathway as 0.67 . The internal consistency coefficient of the questionnaire was 0.89 in Persian version.

This study was conducted on 30 patients with breast cancer in different stages (II, III) who were undergoing chemotherapy; they were randomly divided into 2 experimental and control groups. The collected data were analyzed using the SPSS-20. Descriptive statistics including mean and standard deviation and analytical statistical tests, including Levene's test for homogeneity of variances and analysis of covariance (ANCOVA) were used. P values less than 0.05 were considered significant. To evaluate the effectiveness of ACT on hope of women with breast cancer, after calculating the scores of pretest and posttest in both experimental and control groups, Levene's test for homogeneity of variances and analysis of covariance (ANCOVA) were performed.

\section{Results}

The mean age for treatment and control groups were 43 and 42 years, respectively. In terms of Tests of WithinSubjects Effects, there were 2 time measurement of hope of pretreatment and posttreatment. The present study was performed to examine the effect of ACT on hope in women with breast cancer. Table 1 shows the descriptive statistics related to this analysis, including mean of scores of hope in experimental and control groups at pretest and posttest. Mean score of hope before the experiment was 19.13, which increased after the experiment to 32 . These differences were not observed in the control group.

First, for checking the assumption of normality of subscale (pathway and agency) we used the KolmogorovSmirnov test. According to Table 2, significant posttest pathway and agency is higher than 0.05 indicating that the default is set to perform parametric tests. It is necessary that the assumption of homogeneity of variances variables be examined. The results are reported in Table 3 .

The results also showed that Levene's test and posttest variables pathway $(\mathrm{P}=0.128, \mathrm{~F}(28,1)=2.458)$ and agency $(\mathrm{P}=0.495, \mathrm{~F}(28,1)=0.477)$ means were not significant, indicating that the variances are homogeneous. According to the results of Table 4, the default equality of covariance matrices of observed variables are maintained in different groups $(\mathrm{P}<0.05, \mathrm{~F}=1.459)$. Thus, the multivariate analysis of variance test runs. The results are presented in Table 5. The findings of present study have shown that patients with breast cancer after participating in ACT intervention had experienced higher levels of hope than patients with breast cancer in the control group.

As seen in Table 5, comparison of the results between the two groups with controlling the effect of pre and post test, showed that pathway scores of patients in the ex-

Table 1. Mean differences of hope before and after intervention

\begin{tabular}{cccc}
\hline & \multicolumn{1}{c}{ Variable } & Before Intervention & After Intervention \\
\hline Hope & Experimental group $(n=15)$ & 19.13 & 32 \\
& Control group $(n=15)$ & 16.93 & 16.66 \\
Pathway & Experimental group $(n=15)$ & 11 & 14.06 \\
& Control group $(n=15)$ & 5.53 & 10.66 \\
Agency & Experimental group $(n=15)$ & 8.13 & 14.60 \\
& Control group $(n=15)$ & 7.40 & 9.33 \\
\hline
\end{tabular}


Table 2. Normality of variables pathway and agency posttests

\begin{tabular}{|c|c|c|c|c|}
\hline & & Statistics & df & Sig. \\
\hline \multirow{3}{*}{ Pathway post-test } & Experimental group & 0.17 & 15 & 0.18 \\
\hline & & & & \\
\hline & Control group & 0.16 & 15 & 0.19 \\
\hline \multirow{3}{*}{ Agency post-test } & Experimental group & 0.15 & 15 & 0.20 \\
\hline & & & & \\
\hline & Control group & 0.18 & 15 & 0.17 \\
\hline
\end{tabular}

Table 3. Levene's test for homogeneity of variances

\begin{tabular}{ccccc}
\hline Variable & F & df1 & df2 & Sig. \\
\hline Pathway & 2.458 & 1 & 28 & 0.128 \\
Agency & 0.477 & 1 & 28 & 0.495 \\
\hline
\end{tabular}

perimental group had a significant increase compared to control one. Also, comparison of the results between the two groups with controlling the effect of pre and post test, showed that agency scores of patients in the experimental group had a significant increase compared to control one $(\mathrm{P}<0.001, \mathrm{~F}=279.025)$. Therefore, the hypothesis is confirmed.

Table 4. Equality of variance matrices test results

\begin{tabular}{cc}
\hline Indicators & Value \\
\hline Box's M & 4.744 \\
F & 1.459 \\
df1 & 3 \\
df2 & 141120.000 \\
Sig. & 0.224 \\
\hline
\end{tabular}

\section{Discussion}

This study investigated the effectiveness of ACT on the hope of women with breast cancer. Results showed that ACT intervention has significant effectiveness on the hope of these patients. Few studies have examined effectiveness of ACT techniques in patients with cancer. Following a comprehensive literature search, only a small

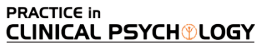

Table 5. Analysis of covariance to compare two groups pretest and posttest

\begin{tabular}{rlcccc}
\hline & Variables & df & MS & F & P value \\
\hline \multirow{3}{*}{ Pretest } & Pathway & 1 & 11.086 & 7.603 & 0.011 \\
& Agency & 1 & 16.513 & 7.254 & 0.012 \\
\multirow{2}{*}{ Posttest } & Pathway & 1 & 105.696 & 72.493 & 0.012 \\
& Agency & 1 & 279.025 & 279.025 & 0.001 \\
\hline
\end{tabular}


number of studies were found that deliberately studied the effectiveness of ACT within the cancer setting, but this nonetheless presents useful pilot data. The data demonstrate potential clinical- and cost-effectiveness for a range of patients, including those with psychological comorbidity. Within the context of wider cancer adjustment, ACT offers an intervention framework to appropriately build upon the strong empirical base already established for mindfulness within this specific patient population. The evidence available suggests that the underlying framework of ACT offers an intervention model that is potentially more suited to the individualistic nature of cancer adjustment (Hulbert-Williams, Storey, \& Wilson, 2015).

In another study, ACT can be an effective intervention approach for patients with cancer that increases acceptance regarding disease and simultaneously leads to improvement in the meaning of life (Datta, Aditya, Chakraborty, Das, \& Mukhopadhyay, 2015). According to Feros et al. (2013) research, ACT effect sizes were comparable to those obtained in studies examining the effectiveness of other psychological therapies, such as cognitive behavior therapy, at improving quality of life among individuals with cancer. Also according to research of Mystakidou et al. (2007), significant correlations were found between hopelessness, depression, and cognitive condition. These findings demonstrate the physical, psychological, and cognitive aspects of patients with cancer. In another research, results showed that ACT significantly decreased scores on depression and psychological flexibility in women with breast cancer (Dehghani Najvani et al., 2015).

Four processes of psychological flexibility; acceptance of illness, values-based action, psychological acceptance, and mindfulness, significantly decrease long term treatment (Hayes et al., 2006).Acceptance and commitment therapy can expand the acceptance belief of lack of control over the life in patients with cancer. The scene of lack of control over life leads to increase of mental Heath problems and is a barrier against medical procedure. Regarding take self as a context with metaphors and techniques and assignments during sessions, it could be effective in the treatment of people in individual therapy sessions (Feros et al., 2013).

In fact, the metaphors of this treatment encourage the patients to identify positive and good experiences and their role in promoting the concept of self recognition, at the same time their ability to accept the negative experiences of life and live in the present moment. In addition, patients who are diffused between thoughts, feelings and behavior, are trained to differentiate between them. Patients often believe that their thoughts are unchangeable truth.
After the treatment they would be able to contemplate and review their beliefs and determine the truth or falsity of their beliefs. These skills, prepare patients to deal with challenges. They can overcome problems rather than be despaired (Strosahl, Hayes, Bergan, \& Romano, 1998).

This study has a number of limitations that must be acknowledged: First is the non-random selection of the participants; second, variables such as occupation and socioeconomic status of patients have not been controlled; third, there was a lack of follow-up periods. This study can be considered a preliminary study to evaluate the effectiveness of therapy based on commitment and acceptance of the patients with cancer. These are some suggestions for future studies. A similar study based on acceptance and commitment therapy can be conducted on men with cancer. It is recommended to do similar research in men's groups due to its similarities with other disease and some other cancer type.

This study investigates the effect of acceptance and commitment therapy on improving hope among women with breast cancer. According to the findings of this research, this treatment can be chosen as a method of psychotherapy and complementary medical treatment can be used to increase hope in patients with cancer. We hope that the results of this research encourage the related experts to focus more on the psychological aspect of this disease that its direct result can be better and faster treatment of disease and improvement of patients' quality of life. Based on this study, we suggest that in future studies both male and female patients be used to increase the generalizability of the results. We also recommend the effectiveness of this intervention be evaluated on people who have cancer in their families.

Subjects were included in study after assuring the confidentiality of their personal information and taking written consents from them. Also in this study, subjects were allowed to refrain from participating at any time they were reluctant to continue cooperation. Research methods did not violate legal, cultural, and Islamic principles.

\section{Acknowledgements}

The present paper was abstracted from the first author's MSc. thesis, Department of Clinical Psychology, Faculty of Management and Accounting, Qazvin Branch, Islamic Azad University. We appreciate all participants in this study and those who helped us in conducting this research.

\section{Conflict of Interest}

The authors declared no conflicts of interest. 


\section{References}

Ahmed, I., Jabeen, K., Inayat, R., \& Hasan, R. (2013). Susceptibility Testing of Extensively Drug-Resistant and Pre-Extensively Drug-Resistant Mycobacterium tuberculosis against Levofloxacin, Linezolid, and Amoxicillin-Clavulanate. Antimicrobial Agents and Chemotherapy, 57(6), 2522-5. doi: 10.1128/ aac.02020-12

Akbari, A., Razzaghi, Z., Homaee, F., Khayamzadeh, M., Movahedi, M., \& Akbari, M. E. (2010). Parity and breastfeeding are preventive measures against breast cancer in Iranian women. Breast Cancer, 18(1), 51-55. doi: 10.1007/s12282-010-0203-Z

American Cancer Society. (2011). Cancer facts and figures for Hispanic/Latinos. Atlanta: American Cancer Society.

Bloy, S., Oliver, J. E., \& Morris, E. (2011). Usingacceptance and commitment therapy with people with psychosis: A case study. Clinical Case Studies, 10(5), 347-359. doi: $10.1177 / 1534650111420863$

Caffarel, M. M., Andradas, C., Pérez-Gómez, E., Guzmán, M., \& Sánchez, C. (2012). Cannabinoids: A new hope for breast cancer therapy? Cancer Treatment Reviews, 38(7), 911-918. doi:10.1016/j.ctrv.2012.06.005

Chang, E. C., Yu, E. A., \& Hirsch, J. K. (2013). On the confluence of optimism and hope on depressive symptoms in primary care patients: Does doubling up on bonum futurun Proffer any added benefits? Journal of Positive Psychology, 8(5), 404411. doi: $10.1080 / 17439760.2013 .818163$

Datta, A., Aditya, C., Chakraborty, A., Das, P., \& Mukhopadhyay, A. (2015). The potential utility of acceptance and commitment therapy (act) for reducing stress and improving wellbeing in cancer patients in Kolkata. Journal of Cancer Education, 31(4), 721-729. doi: 10.1007/s13187-015-0935-8

Dehghani Najvani, B., Neshatdoost, H. T., Abedi, M. R., \& Mokarian, F. (2015). The effect of acceptance and commitment therapy on depression and psychological flexibility in women with breast cancer. Zahedan Journal of Research in Medical Sciences, $17(4)$.

Du, H., \& King, R. B. (2013). Placing hope in self and others: Exploring the relationships among self-construals, locus of hope, and adjustment. Personality and Individual Differences, 54(3), 332-337. doi: 10.1016/j.paid.2012.09.015

Eyles, C., Leydon, G. M., Hoffman, C. J., Copson, E. R., Prescott, P., Chorozoglou, M., \& et al. (2015). Mindfulness for the selfmanagement of fatigue, anxiety, and depression in women with metastatic breast cancer. Integrative Cancer Therapies, 14(1), 42-56. doi: 10.1177/1534735414546567

Falagas, M. E., Zarkadoulia, E. A., Ioannidou, E. N., Peppas, G., Christodoulou, C., \& Rafailidis, P. I. (2007). The effect of psychosocial factors on breast cancer outcome: A systematic review. Breast Cancer Research, 9, R44. doi: 10.1186/bcr1744

Ferlay, J., Shin, H. R., Bray, F., Forman, D., Mathers, C., Parkin, D. M. (2010). Estimates of worldwide burden of cancer in 2008: GLOBOCAN 2008. International Journal of Cancer. 127(12), 2893-917. doi: 10.1002/ijc.25516

Feros, D. L., Lane, L., Ciarrochi, J., \& Blackledge, J. T. (2013). Acceptance and Commitment Therapy (ACT) for improving the lives of cancer patients: a preliminary study. Psycho-Oncology, 22(2), 459-64.
Hayes, S. C., Luoma, J. B., Bond, F. W., Masuda, A., \& Lillis, J. (2006). Acceptance and commitment therapy: Model, processes and outcomes. Behaviour Research and Therapy, 44(1), 1-25. doi: 10.1016/j.brat.2005.06.006

Hayes, S.C., Strosahl, K.D., \& Wilson, K.G. (2011). Acceptance and Commitment Therapy: The process and practice of mindful change $\left(2^{\text {nd }}\right.$ Ed. $)$. New York: Guilford.

Hulbert-Williams, N. J., Storey, L., \& Wilson, K. G. (2014). Psychological interventions for patients with cancer: Psychological flexibility and the potential utility of acceptance and commitment therapy. European Journal of Cancer Care, 24(1), 15-27. doi: $10.1111 /$ ecc. 12223

Jafari, E., Najafi, M., Sohrabi, F., Dehshiri, G. R., Soleymani, E., \& Heshmati, R. (2010). Life satisfaction, spirituality well-being and hope in cancer patients. Procedia - Social and Behavioral Sciences, 5, 1362-1366. doi: 10.1016/j.sbspro.2010.07.288

Jemal, A., Center, M. M., de Santis, C., \& Ward, E. M. (2010). Global patterns of cancer incidence and mortality rates and trends. Cancer Epidemiology Biomarkers \& Prevention, 19(8), 1893-1907. doi:10.1158/1055-9965.epi-10-0437.

Kamio, M., Schmidt, M., Germann, M. W., Kubanek, J., \& Derby, C. D. (2013). The smell of moulting: N-acetylglucosamino-1,5lactone is a premoult biomarker and candidate component of the courtship pheromone in the urine of the blue crab, Callinectes sapidus. Journal of Experimental Biology, 217(8), 1286-96. doi: $10.1242 /$ jeb. 099051

Knaul, F., Arreola-Ornelas, H., Velazquez, E., Dorantes, J., Mendez, O. \& Avila-Burgos L. (2009). [The cost of breast cancer medical care: The case of the Mexican Social Security Institute (Spanish)]. Salud Pública de México, 51(2): 286-295.

Knaul, F., Bustreo, F., Ha, E. \& Langer, A. (2009). Breast cancer: Why link early detection to reproductive health interventions in developing countries? Salud Pública de México, 51(Suppl 2):220-227. PMID: 19967277

Kopans, D. B. (2011). Just the facts: Mammography saves lives with little if any radiation risk to the mature breast. Health Physics, 101(5), 578-582. doi: 10.1097/hp.0b013e3182254e93

Liao, M. N., Chen, S. C., Lin, Y. C., Chen, M. F., Wang, C. H., \& Jane, S. W. (2014). Education and psychological support meet the supportive care needs of Taiwanese women three months after surgery for newly diagnosed breast cancer: A non-randomised quasi-experimental study. International Journal of Nursing Studies, 51(3), 390-399. doi: 10.1016/j.ijnurstu.2013.07.007

Valent, P., Bonnet, D., De Maria, R., Lapidot, T., Copland, M., Melo, J. V., et al. (2012). Cancer stem cell definitions and terminology: the devil is in the details. Nature Reviews Cancer, 12(11), 767-75. doi: 10.1038/nrc3368

Mohabbat-Bahar, S., Maleki-Rizi, F., Akbari, M.E. \& Moradi-Joo, M. (2015). Effectiveness of group training based on acceptance and commitment therapy on anxiety and depression of women with breast cancer. Iranian journal of cancer prevention, 8(2), 71-6. PMID: 25960844

Mustian, K. M., Sprod, L. K., Janelsins, M., Peppone, L. J., Palesh, O. G., Chandwani, K., et al. (2013). Multicenter, randomized controlled trial of yoga for sleep quality among cancer survivors. Journal of Clinical Oncology, 31(26), 3233-3241. doi: 10.1200/jco.2012.43.7707 
Mystakidou, K., Tsilika, E., Parpa, E., Pathiaki, M., Patiraki, E., Galanos, A., \& Vlahos, L. (2007). Exploring the Relationships Between Depression, Hopelessness, Cognitive Status, Pain, and Spirituality in Patients With Advanced Cancer. Archives of Psychiatric Nursing, 21(3), 150-61. doi: 10.1016/j. apnu.2007.02.002

Osborn, R. L., Demoncada, A. C., \& Feuerstein, M. (2006). Psychosocialinterventions for depression, anxiety, and quality of life in cancer survivors: Meta-analyses. The International Journal of Psychiatry in Medicine, 36(1), 13-34. doi: 10.2190/eufnrv1k-y3tr-fk0l

Early Breast Cancer Trialists' Collaborative Group (EBCTCG). Comparisons between different polychemotherapy regimens for early breast cancer: Meta-analyses of long-term outcome among 100000 women in 123 randomized trials. Lancet, 379(14), 432-444. doi: 10.1016/S0140-6736(11)61625-5

Reed, E., Simmonds, P., Haviland, J., \& Corner, J. (2012). Quality of life and experience of care in women with metastatic breast cancer: A cross-sectional survey. Journal of Pain and Symptom Management, 43(4), 747-758. doi: 10.1016/j.jpainsymman.2011.05.005

Ripamonti, C. I., Buonaccorso, L., Maruelli, A., Bandieri, E., Boldini, S. \& Pessi M. A. (2012). Hope herth index (HHI): A validation study in Italian patients with solid and hematological malignancies on active cancer treatment. Tumori, 98(3), 38592. doi: $10.1700 / 1125.12409$

Sanford, S. D., Beaumont, J. L., Butt, Z., Sweet, J. J., Cella, D., \& Wagner, L. I. (2014). Prospective longitudinal evaluation of a symptom cluster in breast cancer. Journal of Pain and Symptom Management, 47(4), 721-730. doi: 10.1016/j.jpainsymman.2013.05.010

Schneider, S., Moyer, A., Knapp-Oliver, S., Sohl, S., Cannella, D., \& Targhetta, V. (2009). Pre-intervention distress moderates the efficacy of psychosocial treatment for cancer patients: a meta-analysis. Journal of Behavioral Medicine, 33(1), 1-14. doi n:10.1007/s10865-009-9227-2

Siegel, R., Naishadham, D., \& Jemal, A. (2013). Cancer statistics, 2013. CA: A Cancer Journal for Clinicians, 63(1), 11-30. doi:10.3322/caac.21166

Stanton, A. L., Danoff-Burg, S., Cameron, C. L., Bishop, M., Collins, C. A., Kirk, S. B., et al. (2000). Emotionally expressive coping predicts psychological and physical adjustment to breast cancer. Journal of Consulting and Clinical Psychology, 68(5), 875-882. doi: 10.1037/0022-006x.68.5.875

Strosahl, K. D., Hayes, S. C., Bergan, J., \& Romano, P. (1998). Assessing the field effectiveness of acceptance and commitment therapy: An example of the manipulated training research method. Behavior Therapy, 29(1), 35-63. doi: 10.1016/s00057894(98)80017-8

Snyder, C. R., Harris, C., Anderson, J. R., Holleran, S. A., Irving, L. M., Sigmon, S. T., et al. (1991). The will and the ways: Development and validation of an individual-differences measure of hope. Journal of Personality and Social Psychology, 60(4), 570-585. doi: 10.1037/0022-3514.60.4.570

Tai, S., \& Turkington, D. (2009). The evolution of cognitive behavior therapy for schizophrenia: Current practice and recent developments. Schizophrenia Bulletin, 35, 865-873.

Tayebi M, Shabestani Monfared A, \& Moslemi D. (2012). [A 10 year survey of cancer in patients who referred to shahid Rajai radiotherapy center in North of Iran (2000-2009) (Persian)]. Journal of Babol University Of Medical Sciences. 14(6), 97-101.

Torre, L. A., Bray, F., Siegel, R. L., Ferlay, J., Lortet-Tieulent, J., \& Jemal, A. (2015). Global cancer statistics, 2012. CA: A Cancer Journal for Clinicians, 65(2), 87-108. doi: 10.3322/caac.21262

Wakiuchi, J., Aparecida Marchi, J., Sharlise Norvila, L., Silva Marcon, S., \& Aparecida Sales, C. (2015). Hope of cancer patients undergoing chemotherapy. Acta Paulista de Enfermagem, 28(3), 202-208. doi: 10.1590/1982-0194201500035 